\title{
Entrepreneurship
}

Jul a Dez $2019-$ v.3 - n.2

ISSN: 2595-4318

This article is also available online at: www.sustenere.co

\section{Rotinas de atendimento em um hospital veterinário universitário: um estudo de caso}

O presente estudo tem como objetivo descrever as rotinas de atendimento a pacientes de um hospital universitário veterinário. Desse modo, esse trabalho possui natureza qualitativa, pois vale-se de um ambiente natural com fonte direta de dados, no qual o pesquisador é instrumento fundamental. O estudo de caso foi realizado no Setor de Clínica Médica de Cães e Gatos e no Setor de Anestesiologia do Hospital Veterinário Universitário Alfa no período de 01 de setembro a 24 de novembro de 2017. Foram acompanhados 169 quadros clínicos e 52 procedimentos anestésicos, no total de 205 cães e 16 gatos. Como resultados, percebeu-se que as rotinas de atendimento a pacientes no HVUA são bem definidas com destaque para o acompanhamento em tempo real do paciente por meio do software de gestão. Constatou-se, com a pesquisa, que o fluxo de atendimento descrito não estava representado graficamente, ainda que os funcionários e colaboradores mais antigos do hospital os conhecesse bem. Desse modo, o presente estudo contribui para a orientação de novos funcionários e posterior aplicação em outras unidades.

Palavras-chave: Clínica Médica; Animais; Administração hospitalar.

\section{Routines of attendance in a veterinary university hospital: a case study}

\begin{abstract}
This paper to describe patient care routines at a university veterinary hospital. In this way, this work has a qualitative nature because it uses a natural environment with a direct data source, in which the researcher is a fundamental instrument. The case study was carried out in the Department of Clinical Medicine of Dogs and Cats and in the Anesthesiology Sector of the Veterinary Hospital of the Alfa University from September 1 to November 24, 2017. A total of 169 clinical pictures and 52 anesthetic procedures, in the total of 205 dogs and 16 cats. As results, it was noticed that the patient care routines in the HVUA are well defined, highlighting the patient's real-time follow-up through the management software. It was found with the research that the flow of care described was not represented graphically, although the employees and older employees of the hospital knew them well. Thus, the present study contributes to the orientation of new employees and subsequent application in other units.
\end{abstract}

Keywords: Medical Clinic; Animals; Hospital administration.

Topic: Planejamento, Estratégia e Competitividade

Reviewed anonymously in the process of blind peer.
Received: $14 / 07 / 2019$

Approved: 27/11/2019
Tuane Ferreira Melo

Universidade Federal de Lavras, Brasil

http://lattes.cnpq.br/7003071033672294

tuaneferreiramelo@gmail.com

Sheldon William Silva (D)

Instituto Federal do Norte de Minas Gerais, Brasil

http://lattes.cnpq.br/5691436224279198

http://orcid.org/0000-0002-2473-5728

sheldonwilliamsilva@gmail.com
Referencing this:

MELO, T. F.; SILVA, S. W.. Rotinas de atendimento em um hospital veterinário universitário: um estudo de caso. Entrepreneurship, v.3, n.2, p.1-12, 2019. DOI: http://doi.org/10.6008/CBPC2595$\underline{4318.2019 .002 .0001}$ 


\section{INTRODUÇÃO}

As organizações vêm enfrentando continuamente mudanças que alteram suas formas de gestão. Cada vez mais, torna-se necessário atualizar os processos de administração para sobrevivência no mercado. Ainda que a maioria das organizações da saúde tenham características bem homogêneas, as diversas normas sanitárias e o contexto regional influenciam sobremaneira na administração hospitalar. Desse modo, carecem ainda de estudos profundos que possam destacar essas peculiaridades.

O presente estudo tem como objetivo descrever as rotinas de atendimento a pacientes de um hospital universitário veterinário. Ainda que a quantidade de pesquisas que tratam da gestão de unidades hospitalares seja incipiente, persiste o desafio de analisar e demonstrar modelos referentes aos procedimentos de saúde animal adotados em hospitais veterinários. As organizações hospitalares são estruturas complexas e precisa formular estratégias que possam ultrapassar a visão exclusiva dos serviços prestados e garantir a eficiência e eficácia dos processos que envolvem a saúde.

O trabalho possui natureza qualitativa pois vale-se de um ambiente natural com fonte direta de dados, no qual o pesquisador é instrumento fundamental. A pesquisa foi realizada no período compreendido entre os dias 1 de setembro a 24 novembro de 2017, de segunda à sexta feira das 08:00 às 12:00 e das 14:00 às 18:00, no setor de Clínica Médica de Pequenos Animais e no setor de Anestesiologia do departamento de Medicina Veterinária da Universidade Alfa. Foram acompanhados 169 quadros clínicos e 52 procedimentos anestésicos, no total de 205 cães e 16 gatos. Descreve-se nessa pesquisa os procedimentos padrões realizados desde a recepção no paciente até a conclusão do caso.

Como resultados, percebeu-se que as rotinas de atendimento a pacientes no HVUA são bem definidas com destaque para o acompanhamento em tempo real do paciente por meio do software de gestão. Constatou-se com a pesquisa que o fluxo de atendimento descrito não estava representado graficamente, ainda que os funcionários e colaboradores mais antigos do hospital os conhecesse bem. Os procedimentos de atendimento analisados corroboram com as premissas encontradas nos estudos de Lin et al. (2010), nos quais os veterinários que atuam como gestores devem se preocupar com o atendimento conferido ao paciente e ao tutor, ultrapassando as percepções do componente médico do atendimento.

\section{REVISÃO TEÓRICA}

De acordo com Mintzberg (1995), a organização hospitalar se caracteriza por ser uma burocracia profissional do ponto de vista estrutural, onde o setor operacional tem importância, traciona e concentra o poder na organização. O seu mecanismo de controle se dá por padronização de habilidades realizadas por órgãos fiscalizadores externos das diversas categorias profissionais. Desse modo, Azevedo (1993) destaca que as organizações hospitalares são estruturas complexas, pois apresentam equipe multidisciplinar autônoma para dar assistência à saúde em caráter preventivo, curativo e reabilitador a pacientes em regime de internação. Cabe destacar ainda as características notadamente explícitas nos hospitais universitários, constituídos como espaço de prática de ensino-aprendizagem e produção científica. 
Ansoff (1985) conceitua gestão como um processo ativo de determinação e orientação do caminho a ser seguido por uma organização para a realização de seus objetivos, compreendendo um conjunto de análises, decisões, comunicação, liderança, motivação, avaliação, controle, entre outras atividades próprias da administração. Para Hamel et al. (1997), uma organização tem como função a busca pela diversificação de seus aspectos competitivos, formulando as estratégicas que possam ultrapassar a visão exclusiva em produtos, passando à visão de recursos, competências e capacidades exclusivas a organização. Nesse sentido, a combinação perfeita de Recursos e Capacidades gera Competências Essenciais, as quais garantem a sobrevivência, competitividade e sucesso de uma organização no mercado.

Ainda que o cenário da administração hospitalar se enquadre como uma organização prestadora de serviços, ela necessita de atributos de gestão, principalmente dedicados ao planejamento de suas atividades, conforme demonstrado por Ackoff (1974). De acordo com o autor, o planejamento é um processo contínuo que envolve um conjunto complexo de decisões inter-relacionadas que podem ser separadas de formas diferentes. O planejamento dessas ações é imprescindível para garantir a eficácia e eficiência dos serviços prestados. Atividades organizadas colaboram para o diagnóstico de enfermidades e posterior recuperação do paciente. Nesse sentido é indispensável que se considere que um hospital é uma estrutura viva, de alto dinamismo operacional, com atividades caracteristicamente polimorfas, que envolve uma gama muito diversificada de aspectos (RUTHES et al., 2007).

D'innocenzo et al. (2006) alertam para um movimento pela qualidade nos serviços de Saúde e Enfermagem. De acordo com os autores, trata-se de uma necessidade incorporada à gestão dessas áreas a fim de assegurar a assistência livre de riscos ao usuário, que implica na conscientização de toda a equipe quanto à sua importância e ao valor de suas ações. No Brasil ainda que não existam muitos estudos dedicados a temática da gestão em hospitais veterinários, Lin et al. (2010) argumentam que os gestores de instalações médicas veterinárias precisam de insights sobre a natureza da qualidade do atendimento. Esse cuidado é o resultado do processo. O gerenciamento de processos conota um conjunto de práticas que combinam abordagens metodológicas com o gerenciamento de recursos humanos, e elas são implementadas para gerenciar e melhorar os processos que produzem produtos e serviços.

Lin et al. (2010) destacam que todos os processos devem ser definidos, medidos, analisados e aprimorados continuamente. Muitos hospitais humanos estão agora introduzindo programas de controle de qualidade e monitoramento. Uma gestão das rotinas de atendimento pode não produzir atendimento de qualidade, mas permitirá que os gestores avaliem a qualidade dos cuidados. Informações sobre a qualidade do processo fornecem dados com os quais determinar as melhores decisões de gerenciamento para a implementação de ações para melhorar o processo. As avaliações de qualidade devem ser consistentes e confiáveis o suficiente para permitir distinções de variações de processo controláveis, conforme mencionado anteriormente.

\section{METODOLOGIA}

O objetivo principal desta pesquisa foi descrever as rotinas de atendimento a pacientes de um 
hospital universitário veterinário. De acordo com Gil (2002), pode-se definir pesquisa como “o procedimento racional e sistemático que tem como objetivo proporcionar respostas aos problemas que são propostos". A pesquisa é de natureza qualitativa, pois de acordo Richardson (1999), são estudos que empregam a metodologia qualitativa podem descrever a complexidade de determinado problema, analisar a interação de certas variáveis, compreender e classificar processos dinâmicos vividos por grupos sociais. Corroborando, Neves (1996) destaca que nas pesquisas qualitativas o pesquisador procura entender com frequência os fenômenos, segundo a perspectiva dos participantes da situação estudada e, a partir daí, situe sua interpretação dos fenômenos estudados".

A pesquisa pode ser classificada, de acordo com Vergara et al. (2003), em relação a dois aspectos: quanto aos fins e quanto aos meios de investigação. Com relação aos fins, a pesquisa é descritiva, levandose em consideração o fato de que a mesma pretende obter e descrever as rotinas de atendimento a pacientes de um hospital universitário veterinário. De acordo com Gil (2002) "as pesquisas descritivas têm como objetivo primordial a descrição das características de determinada população ou fenômeno ou, então, o estabelecimento de relações entre variáveis". Quanto aos meios, a presente pesquisa é um estudo de caso. De acordo com Yin (2001) o estudo de caso é escolhido "ao se examinarem acontecimentos contemporâneos, mas quando não se podem manipular comportamentos relevantes". Segundo Gil (2002) o estudo de caso consiste no estudo profundo e exaustivo de um ou de poucos objetos, de maneira a permitir o seu conhecimento amplo e detalhado.

A pesquisa foi caracterizada pela observação durante atividades práticas de estágio supervisionado realizado no Hospital Veterinário Universitário Alfa - HVUA, localizado na em uma cidade da região da Zona da Mata do Estado de Minas Gerais. O nome da Universidade e do Hospital foram preservados por caráter de sigilo de pesquisa. O Hospital Veterinário Universitário Alfa (HVUA) possui uma estrutura física que possibilita acompanhamento da rotina veterinária hospitalar completa por ser um hospital escola. Dessa forma, o HVUA tem atividades direcionadas a graduação, pós-graduação e a comunidade. De acordo com Gil (2002), a observação é um método de investigação que pode ser utilizada como uma etapa para complementar outros procedimentos investigativos.

A pesquisa foi realizada no período compreendido entre os dias 1 de setembro a 24 novembro de 2017, de segunda à sexta feira das $08: 00$ às $12: 00$ e das 14:00 às 18:00, no setor de Clínica Médica de Pequenos Animais e no setor de Anestesiologia do departamento de Medicina Veterinária do Hospital Veterinário Universitário Alfa. Foram acompanhados 169 quadros clínicos e 52 procedimentos anestésicos, no total de 205 cães e 16 gatos.

\section{RESULTADOS E DISCUSSÃO}

\section{Características do Hospital Veterinário e equipe profissional}

O HVUA funciona 24 horas por dia, todos os dias, incluindo finais de semana e feriados, sendo que o horário de atendimento é de segunda à sexta feira, de 08 horas às 12 horas e de 14 horas às 18 horas. Durante 
os finais de semana e feriados são atendidos somente os pacientes em internamento. São disponibilizadas oito senhas para casos novos, em cada turno. Os procedimentos cirúrgicos e exames de imagem são agendados conforme a disponibilidade de realização seguindo o horário de funcionamento, exceto casos emergenciais. Dessa forma, são atendidos, em média diária 50 animais (cães e gatos), abrangendo os setores de clínica, cirurgia e diagnóstico por imagem.

O HVUA possui vários profissionais, 13 médicos veterinários residentes do primeiro ano (MVR-1) e 12 médicos veterinários residentes do segundo ano (MVR-2), professores, pós-graduandos, médicos veterinários contratados e graduandos em estágio supervisionado, além de outros funcionários, como técnicos, farmacêuticos e recepcionistas. Ao chegar ao HVUA, o primeiro contato do paciente com o Médico Veterinário se dá na triagem, cujo atendimento ocorria no período de 07:30 às 11:30 horas, e 13:30 às 17:30 horas, de segunda à sexta feira. Posteriormente, o paciente é encaminhado para as consultas. Os atendimentos são realizados por ordem de chegada, exceto os casos emergenciais, casos agendados antecipadamente, cirurgias agendadas antecipadamente, exames de imagem, incluindo retornos e consultas com especialistas.

Todas as atividades são controladas pelo Sistema de Gerenciamento do Hospital Veterinário que integra todos os setores do hospital, fornecendo todos os dados do paciente desde a primeira consulta. Os dados da consulta (anamnese, exame físico, exames complementares, diagnóstico, receituário comum, receituário especial), assim como solicitações de medicações, pedidos de agendamento e exames, são realizados pelo sistema, conforme apontado na Figura 1.

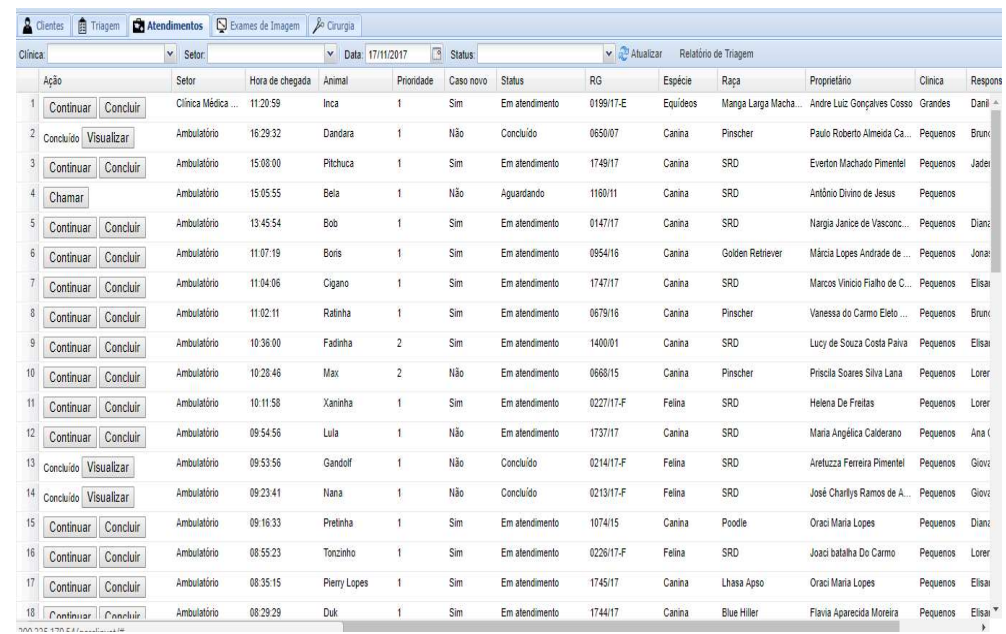

Figura 1: Ficha eletrônica de gerenciamento do HVUA.

\section{Descrição dos casos acompanhados}

Os casos acompanhados durante o período de estágio supervisionado no HVUA estão expostos nas Tabelas 1 a 4, de acordo com a espécie, padrão racial, sistema acometido e procedimento anestésico. Foram acompanhados 205 pacientes caninos e 16 pacientes felinos, totalizando 221 casos no período de 1 de setembro a 24 novembro de 2017. No mês de setembro, foi possível acompanhar os atendimentos clínicos de 90 caninos e 9 felinos. No mês de outubro, foram 50 caninos e 2 felinos nos procedimentos anestésicos. Já no mês de novembro, foram 65 caninos e 5 felinos no atendimento clínico. A maior incidência de 
atendimento foi de caninos e felinos sem raça definida.

Tabela 1: Número absoluto (n) e frequência (\%) de animais acompanhados, no HVUA, de acordo com a espécie, nos meses de setembro, outubro e novembro de 2017.

\begin{tabular}{|l|l|l|l|l|l|l|l|l|}
\hline \multirow{2}{*}{ Espécie } & \multicolumn{2}{|l|}{ Oetembro } & \multicolumn{2}{l|}{ Outubro } & \multicolumn{2}{l|}{ Novembro } & \multicolumn{2}{l|}{ Total Geral } \\
\cline { 2 - 9 } & $\mathbf{n} \mathbf{0}$ & $\mathbf{\%}$ & $\mathbf{n o}$ & $\mathbf{6}$ & $\mathbf{n} \mathbf{0}$ & $\mathbf{\%}$ & no & \% \\
\hline Canina & 90 & $90,9 \%$ & 50 & $96,2 \%$ & 65 & $92,9 \%$ & $\mathbf{2 0 5}$ & $92,8 \%$ \\
\hline Felina & 9 & $9,1 \%$ & 2 & $3,8 \%$ & 5 & $7,1 \%$ & $\mathbf{1 6}$ & $7,2 \%$ \\
\hline Total & $\mathbf{9 9}$ & $\mathbf{1 0 0} \%$ & $\mathbf{5 2}$ & $\mathbf{1 0 0 \%}$ & $\mathbf{7 0}$ & $\mathbf{1 0 0} \%$ & $\mathbf{2 2 1}$ & $\mathbf{1 0 0 \%}$ \\
\hline
\end{tabular}

Tabela 2: Número absoluto (n) e frequência (\%) de cães e gatos acompanhados no HVUA, de acordo com o padrão racial, no período de 01 de setembro a 24 de novembro de 2017.

\begin{tabular}{|c|c|c|c|}
\hline Espécie & Raça & no & $\%$ \\
\hline \multirow[t]{28}{*}{ Canina } & Sem Raça Definida (SRD) & 81 & $39,5 \%$ \\
\hline & Poodle & 21 & $10,2 \%$ \\
\hline & Yorkshire Terrier & 19 & $9,3 \%$ \\
\hline & Pinscher & 19 & $9,3 \%$ \\
\hline & Rottweiler & 8 & $3,9 \%$ \\
\hline & Chow-chow & 6 & $2,9 \%$ \\
\hline & Shih Tzu & 6 & $2,9 \%$ \\
\hline & Buldogue Francês & 5 & $2,4 \%$ \\
\hline & Pit Bull & 5 & $2,4 \%$ \\
\hline & Maltês & 3 & $1,5 \%$ \\
\hline & Golden Retriever & 3 & $1,5 \%$ \\
\hline & Akita & 3 & $1,5 \%$ \\
\hline & Dachshund & 3 & $1,5 \%$ \\
\hline & Border Collie & 3 & $1,5 \%$ \\
\hline & Pastor Alemão & 3 & $1,5 \%$ \\
\hline & Australian Cattle Dog & 2 & $1,0 \%$ \\
\hline & Boxer & 2 & $1,0 \%$ \\
\hline & Lhasa Apso & 2 & $1,0 \%$ \\
\hline & Labrador Retriever & 2 & $1,0 \%$ \\
\hline & Buldogue Campeiro & 1 & $0,5 \%$ \\
\hline & Fila Brasileiro & 1 & $0,5 \%$ \\
\hline & Schnauzer & 1 & $0,5 \%$ \\
\hline & Cocker Spaniel Americano & 1 & $0,5 \%$ \\
\hline & Pug & 1 & $0,5 \%$ \\
\hline & Doberman & 1 & $0,5 \%$ \\
\hline & Pastor de Malinois & 1 & $0,5 \%$ \\
\hline & Pastor Maremano Abruzês & 1 & $0,5 \%$ \\
\hline & Dálmata & 1 & $0,5 \%$ \\
\hline Total & & 205 & $100 \%$ \\
\hline \multirow[t]{2}{*}{ Felina } & Sem Raça Definida (SRD) & 15 & $93,8 \%$ \\
\hline & Persa & 1 & $6,3 \%$ \\
\hline Total & & 16 & $100 \%$ \\
\hline
\end{tabular}

Dentre os sistemas mais frequentes observados nos atendimentos clínicos acompanhados, durante os meses de setembro e novembro, destacam-se as afecções tegumentares em caninos e em felinos, as afecções do trato geniturinário, conforme Tabela 3. Esse resultado de maior frequência das afecções tegumentares em cães é devido à dermatopatias serem comuns em pequenos animais e constantemente são vistas na clínica veterinária, pois representa aproximadamente 21 a 42\% dos casos atendidos (BACHIR et al., 2011; CARDOSO et al., 2011). Durante o mês de outubro, no qual foi realizado o estágio no Setor de Anestesiologia do HVUA foram acompanhados 45 procedimentos anestésicos em cirurgias e 7 em procedimentos anestésicos ambulatoriais. 
Tabela 3: Número absoluto (n) e frequência (\%) de cães e gatos acompanhados no HVUA, de acordo com o sistema acometido ou afecções, no mês setembro e novembro durante o estágio no Setor de Clínica Médica de Cães e Gatos.

\begin{tabular}{|c|c|c|c|c|c|c|}
\hline Atendimento clínico & Caninos & & Felinos & & Total & \\
\hline Sistemas/Afecções & no & $\%$ & no & $\%$ & no & $\%$ \\
\hline Tegumentar e Anexos & 29 & $18,7 \%$ & 0 & $0,0 \%$ & 29 & $17,2 \%$ \\
\hline Afecções Neoplásicas & 27 & $17,4 \%$ & 2 & $14,3 \%$ & 29 & $17,2 \%$ \\
\hline Geniturinário & 11 & $7,1 \%$ & 8 & $57,1 \%$ & 19 & $11,2 \%$ \\
\hline Distúrbio Multissistêmicos & 16 & $10,3 \%$ & 2 & $14,3 \%$ & 18 & $10,7 \%$ \\
\hline Gastrointestinal & 13 & $8,4 \%$ & 2 & $14,3 \%$ & 15 & $8,9 \%$ \\
\hline Osteomuscular & 11 & $7,1 \%$ & 0 & $0,0 \%$ & 11 & $6,5 \%$ \\
\hline Órgãos dos Sentidos & 10 & $6,5 \%$ & 0 & $0,0 \%$ & 10 & $5,9 \%$ \\
\hline Nervoso & 9 & $5,8 \%$ & 0 & $0,0 \%$ & 9 & $5,3 \%$ \\
\hline Afeç̧ões Hematológicas & 8 & $5,2 \%$ & 0 & $0,0 \%$ & 8 & $4,7 \%$ \\
\hline Endócrino & 8 & $5,2 \%$ & 0 & $0,0 \%$ & 8 & $4,7 \%$ \\
\hline Cardiovascular & 7 & $4,5 \%$ & 0 & $0,0 \%$ & 7 & $4,1 \%$ \\
\hline Respiratório & 6 & $3,9 \%$ & 0 & $0,0 \%$ & 6 & $3,6 \%$ \\
\hline Total & 155 & $100,0 \%$ & 14 & $100,0 \%$ & 169 & $100,0 \%$ \\
\hline
\end{tabular}

Tabela 4: Número absoluto (n) e frequência (\%) de cães e gatos acompanhados no HVUA, de acordo com o procedimento anestésico (cirúrgico ou ambulatorial), no mês de outubro durante o estágio no Setor de Anestesiologia.

\begin{tabular}{|c|c|c|c|c|c|c|}
\hline Procedimento Anestésico & Caninos & & Felinos & & Total & \\
\hline & no & $\%$ & no & $\%$ & no & $\%$ \\
\hline Cirúrgico & 44 & $88,0 \%$ & 1 & $50 \%$ & 45 & $86,5 \%$ \\
\hline Ambulatorial & 6 & $12,0 \%$ & 1 & $50 \%$ & 7 & $13,5 \%$ \\
\hline Total & 50 & $100,0 \%$ & 2 & $100 \%$ & 52 & $100,0 \%$ \\
\hline
\end{tabular}

\section{Caracterização da rotina de atendimento aos pacientes e representação}

O processo de atendimento inicia-se na recepção, cujo local recebe os proprietários se dirigem para solicitar o atendimento. Esse espaço possui uma mesa tipo escritório, cadeiras, computador (com software de gerenciamento), impressoras e uma campainha de emergência para acionar a equipe médica disponível para socorros imediatos. Na recepção, a secretária distribui as senhas junto com as resenhas do animal, cadastrando os dados do paciente, com seu número de registro (RG) e os dados do tutor no software de Gerenciamento do Hospital Veterinário, que possui todas as informações do atendimento, inclusive a solicitação de exames laboratoriais e materiais à farmácia e também permite a edição, registro e acesso imediato pelos residentes, recepção, farmácia e laboratório de análises clínicas. Posteriormente os pacientes são encaminhados à sala de triagem. Quando se trata de atendimento emergencial, os veterinários são chamados e o paciente é atendido imediatamente, mesmo sem ter realizado o cadastro, que é feito posteriormente.

A Sala de Triagem é composta por mesa do tipo escritório com cadeira, computador (com software de gerenciamento), mesa de aço inoxidável para atendimento, balança, armário para materiais, mordaças para contenção física de pacientes agressivos, duas lixeiras (uma para descarte de lixo comum e outra para material infectante), caixa para descarte de materiais perfurocortantes e campainha de emergência. Esse local é destinado ao médico veterinário residente do primeiro ano (MVR-1) para realizar a consulta prévia, preencher a ficha de triagem, determinar a prioridade de atendimento com base na gravidade de seu estado e encaminhar o paciente ao setor que melhor se adequa ao quadro. A ficha preenchida na sala de triagem é disponibilizada virtualmente por meio do software já citado, de acordo com o setor ao qual o animal foi encaminhado. Em situações emergenciais, o MVR-1 responsável pela triagem aciona uma campainha na 
triagem do HVUA, para que os responsáveis pela emergência e outros envolvidos sejam avisados para o atendimento do paciente.

A Sala de Emergência é composta por dois monitores multiparamétricos, duas mesas de inox com colchonetes térmicos, dois berços hospitalares com colchonetes térmicos, incubadora, mordaças para contenção física de pacientes agressivos, monitores cardíacos, tubulações para oxigênio, mesa tipo escritório, cadeiras, computador (com software de gerenciamento), ar condicionado, quatro lixeiras (duas para descarte de lixo comum e duas para material infectante), duas caixas para descarte de materiais perfurocortantes, duas pias, duas bandeja com álcool, algodão e gaze e armário com fármacos e materiais usados em casos emergenciais, como ambu, luvas de procedimento, seringas, agulhas, entre outros. Além de campainha de emergência para acionar a equipe médica disponível para socorros imediatos

Apenas pacientes em estado crítico que necessitam de monitoramento intensivo para auxiliar a manutenção da vida são encaminhados para a sala de emergência. Esses animais são constantemente assistidos pelos médicos veterinários do segundo e primeiro ano (MVR-2 e MVR-1) e estagiários. Pacientes sob quimioterapia e usando fármacos de risco colateral potencial são monitorados também nessa sala.

A Sala de Moléstias Infecciosas (MI) é composta por uma mesa de aço inoxidável para realização dos procedimentos ambulatoriais, suportes para fluidoterapia, dois conjuntos de gaiolas em inox, mordaças para contenção física de pacientes agressivos, mesa tipo escritório, cadeiras, computador (com software de gerenciamento), duas lixeiras (uma para descarte de lixo comum e outra para material infectante), caixa para descarte de materiais perfurocortantes, pia, bandeja com álcool, algodão e gaze, dois termômetros de uso restrito aos internados nessa sala e campainha de emergência. O paciente apresentado à triagem com suspeita de doença infectocontagiosa, em especial parvovirose ou cinomose, é encaminhado para o internamento, na sala de $\mathrm{MI}$, até que os resultados dos exames complementares fiquem prontos para confirmação, ou não, do diagnóstico. Os pacientes internados com tal diagnóstico são mantidos nessa sala, isolados dos demais internados, a fim de evitar a propagação da enfermidade. O atendimento desses casos é realizado pelos MVR-2 e MVR-1, responsáveis ao momento pelo Setor de Moléstias Infecciosas. A sala de MI tem como objetivo evitar a contaminação nas dependências do HVUA, pois ao final do atendimento, a sala passa por desinfecção com vassoura de fogo.

O HVUA é dotado de cinco consultórios destinado ao atendimento de pequenos animais, dois consultórios para atendimentos clínicos, um para atendimento dermatológico e dois para atendimento ambulatorial. Todos os consultórios possuem mesa de aço inoxidável, mesa tipo escritório, computador (com software de gerenciamento), duas cadeiras, mordaças para contenção física de pacientes agressivos, papel toalha, duas lixeiras (uma para descarte de lixo comum e outra para material infectante), caixa para descarte de materiais perfurocortantes e bandeja com álcool, algodão e gaze. O consultório dermatológico, além de toda a estrutura já citada, possui ainda uma lupa para exame dermatológico e materiais para preparo dos exames dermatológicos auxiliares.

Nos consultórios são realizados a anamnese, exame físico e coleta de material para exames complementares. Também são realizadas avaliações mais específicas, como exames neurológicos e 
ortopédicos. As consultas são iniciadas pelo estagiário juntamente com o residente responsável pelo caso. É realizado a anamnese, exame físico do paciente e exames complementares necessários. Após havia discussão do caso com o professor responsável pelo atendimento no dia. Todas as informações eram registradas no sistema de gerenciamento do Hospital Veterinário. A ficha eletrônica no software de Gerenciamento do Hospital Veterinário tem a anamnese de atendimento diferente entre o atendimento clínico geral e do atendimento dermatológico, permitindo uma exploração melhor do sistema acometido.

A Sala de Internamento dispõe de cinco conjuntos de gaiolas em aço inoxidável, duas mesas de inox, mesa tipo escritório, computador (com software de gerenciamento), cadeiras, armários para materiais, geladeira, micro-ondas, mordaças para contenção física de pacientes agressivos, quatro lixeiras (duas para descarte de lixo comum e duas para material infectante), duas caixas para descarte de materiais perfurocortantes, pia e bandeja com álcool, algodão e gaze. Este local fica sob responsabilidade de um MVR2. A sala de internamento é destinada aos pacientes internados, aos pacientes que necessitam apenas de reposição hidroeletrolítica e/ou medicação intravenosa durante o dia e aos pacientes que estão em quimioterapia. Nos dois últimos casos, é fundamental a presença do tutor para fazer companhia ao paciente.

O setor de oncologia é um local destinado à manipulação de medicamentos oncológicos. A sala possui uma cabine de segurança, uma capela de fluxo laminar, bancada, cadeiras, duas lixeiras (uma para descarte de lixo comum e outra para material infectante) e caixa para descarte de materiais perfurocortantes, pia e bandeja com álcool, algodão e gaze.

A Farmácia possui uma mesa tipo escritório, cadeiras, computador (com software de gerenciamento), armários para medicamentos e materiais, duas geladeiras, mesa inox, duas lixeiras (uma para descarte de lixo comum e outra para material infectante) e caixa para descarte de materiais perfurocortantes. Todas as medicações, pomadas e instrumentais para exames específicos (otoscópio, espéculo vaginal, oftalmoscópio, martelo) são armazenados na farmácia. A farmácia destina-se aos setores que envolvem a área de pequenos animais e eles se comunicam por meio do sistema de software de gerenciamento. Para retirar os medicamentos e materiais da farmácia, é necessário requisitar pelo sistema digital, assim a farmácia lança os valores referentes aos produtos diretamente no prontuário do animal e disponibiliza os produtos ao residente. Os materiais são preparados sob a forma de kits, identificados com os dados do paciente, tutor e médico veterinário responsável pelo atendimento.

Os materiais biológicos são armazenados em refrigerador exclusivo, no qual há rigoroso controle da temperatura e higienização. Também há rígida administração sobre medicações controladas, as quais são mantidas em armário trancado, sendo aberto apenas sob o consentimento do farmacêutico. Além disso, embora as medicações oncológicas sejam armazenadas no local, sua manipulação só é realizada na sala de oncologia, a qual é dotada de aparato de proteção para o manipulador.

O Laboratório de Análises Clínicas é composto por diversos aparelhos e profissionais especializados para a realização dos exames complementares. Os equipamentos são microscópicos ópticos, aparelho bioquímico (Refletron plus), aparelho hematológico veterinário ( $A B C$ Vet), aparelho de hemogasometria (Cobas b 121 - Roch), homogeneizador de sangue, banhos-maria e outros. Toda semana há um MVR-1 
responsável pela realização dos exames nesse setor. Vários exames são realizados, como hemograma, análise bioquímica do soro (dosagem das enzimas ALT, AST, GGT e FA, Ureia, Creatinina, Glicose, Colesterol, Proteína, Sódio, Potássio e etc.), hemogasometria, parasitológico de fezes, parasitológico de pele, avaliação de líquidos (pleura, peritoneal, pericárdio e sinovial), líquor e urinálise.

Os materiais coletados para exames no HVUA, tanto de pequenos animais e grandes animais, são enviados para o laboratório clínico. As solicitações dos exames são realizadas no software de gerenciamento e as amostras são identificadas com o número de requisição, gerado pelo sistema, e encaminhados ao laboratório. Os resultados dos exames são lançados no próprio sistema.

O Setor de Diagnóstico por Imagem é composto pela sala de ultrassonografia, de radiologia e de endoscopia para realização de exames de imagem. Os resultados dos exames de imagem são lançados no software de gerenciamento. Na sala de ultrassonografia são realizados exames ultrassonográficos e exames ecocardiográficos pelo MVR-2 do setor ou por professores. Para realização da radiografia, o paciente precisa ter dois acompanhantes para ajudar no posicionamento. A radiografia é realizada por técnico e enviada aos cuidados do MVR-1 e MVR-2, responsáveis pelo setor. A endoscopia é realizada por um docente especializado em gastroenterologia junto com algum MVR-2 da anestesia, este monitorando o animal durante todo o procedimento.

A sala pré-operatória é o local que prepara o paciente para o procedimento cirúrgico. Essa sala é composta por duas mesas inox, cilindro de oxigênio, balança, armário para materiais, máquinas de tricotomia, mordaças para contenção física de pacientes agressivos, duas lixeiras (uma para descarte de lixo comum e outra para material infectante), caixa para descarte de materiais perfurocortantes, pia e bandeja com álcool, algodão e gaze.

Os pacientes encaminhados à cirurgia (previamente marcadas) são recebidos pelos MVR-1 e MVR-2 da cirurgia e são encaminhados à sala pré-operatória. Nesse local, os pacientes são preparados para cirurgia, realiza-se a tricotomia, administra a medicação pré-anestésica (MPA) e se necessário, também realiza a indução anestésica. Após a MPA ou indução anestésica, os pacientes são encaminhados ao bloco cirúrgico por meio de macas.

O Bloco Cirúrgico do HVUA é o local onde se realizam os procedimentos cirúrgicos e possui uma infraestrutura para realização de várias cirurgias em pequenos animais. Na entrada do bloco cirúrgico há uma área para se colocar toucas, propé e máscaras. O bloco cirúrgico é composto por uma sala para os cirurgiões realizarem a antissepsia e duas salas equipadas para cirurgia. Os materiais esterilizados são mantidos em armários dentro das salas de cirurgia, onde se encontra instrumentais, panos de campo, compressas, materiais para curativo, agulhas, cateteres, seringas e outros.

Cada sala de cirurgia possui duas mesas cirúrgicas em aço inox com elevação automática, dois focos luminosos, dois aparelhos de anestesia inalatória, dois monitores de parâmetros vitais, armários para materiais, duas lixeiras (uma para descarte de lixo comum e outra para material infectante), caixa para descarte de materiais perfurocortantes e bandeja com álcool, algodão e gaze. A sala cirúrgica 1 apresenta a mais que a sala cirúrgica 2, computador (com software de gerenciamento), uma câmera e televisor para 
transmissão da cirurgia, possibilitando melhor visualização do procedimento durante as aulas práticas. Além disso, o bloco cirúrgico é dotado de ultrassom dentário (usado para remoção de placas bacterianas dentárias). No acesso entre as salas e a área suja do bloco cirúrgico fica uma maca de aço inoxidável para transportar os pacientes antes e após a cirurgia.

A Sala de Pós-Operatório é local em que os pacientes se recuperam da anestesia. Esse local é composto por baias e um armário de materiais. Os pacientes após a cirurgia são encaminhados por meio de maca até a sala de pós-operatório. Nesse local, são colocados na baia e são monitorados constantemente até a recuperação anestésica.

A sala dos residentes é o local destinado aos médicos veterinários participantes do aprimoramento profissional para discutir os casos, prescrever as receitas, entrarem em contato com os tutores e nas horas vagas, poderem descansar. Esse local conta com bancadas, armários, mesas, cadeiras, computador (com software de gerenciamento) e impressoras. Mediante observação dos procedimentos para atendimento do hospital veterinário, criou-se um fluxo organizado para visualização gráfica do processo de atendimento a pacientes do HVUA, conforme Figura 2.

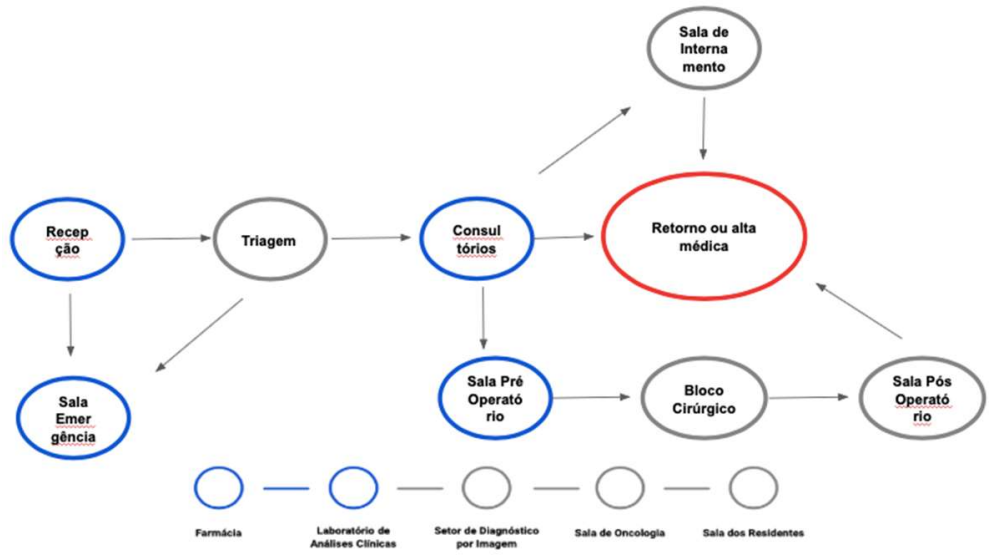

Figura 2: Fluxo das rotinas de atendimento do HVUA.

\section{CONCLUSÕES}

De acordo com as rotinas de atendimento a pacientes de um hospital universitário veterinário, a presente pesquisa representou, de forma gráfica, o fluxo de procedimentos do HVUA, descrevendo com detalhes cada processo desenvolvido desde a recepção do paciente até a conclusão do caso. Considera-se também a extensa casuística no com o total de 205 cães e 16 gatos.

Percebe-se que as rotinas de atendimento a pacientes no HVUA são bem definidas com destaque para o acompanhamento em tempo real do paciente por meio do software de gestão. Constatou-se com a pesquisa que o fluxo de atendimento descrito não estava representado graficamente, ainda que os funcionários e colaboradores mais antigos do hospital os conhecesse bem. Desse modo, o presente estudo contribui para a orientação de novos funcionários e posterior aplicação em outras unidades.

Destaca-se ainda a oportunidade de participação ativa do pesquisador no processo de ensino e aprendizagem a partir de situações reais de vida do contexto da Medicina Veterinária em um Hospital Veterinário Universitário. O HVUA é merecidamente reconhecido por sua estrutura e serviços prestados, 
como exemplo a existência de um sistema operacional organizado e computadorizado. Possui um quadro profissional composto por professores e residentes de excelência, que concede aos estagiários, espaço para a discussão a respeito da melhor conduta clínica e anestésica, fazendo-se possível a construção do raciocínio clínico e pensamento crítico.

Os procedimentos de atendimento analisados corroboram com as premissas encontradas nos estudos de Lin et al. (2010), nos quais os veterinários que atuam como gestores devem se preocupar com o atendimento conferido ao paciente e ao tutor, ultrapassando as percepções do componente médico do atendimento. Desse modo, verifica-se que o mapeamento e descrição dos processos são importantes para alcançar resultados satisfatórios no atendimento a pacientes e eficiência no processo de diagnóstico e acompanhamento médico por parte dos profissionais e médicos veterinários.

Como limitações da pesquisa, destaca-se que a administração hospitalar, tanto no contexto humano quanto no contexto animal, carece de maiores estudos sobre modelos aplicados a gestão dessas organizações. Esta pesquisa não pretende enaltecer forças ou fraquezas do modelo analisado, entretanto, estudos futuros podem realizar análises qualitativas e quantitativas da eficiência organizacional dos procedimentos analisados.

\section{REFERÊNCIAS}

ACKOFF, R. L.. Redesigning the future. New York, 1974.

ANSOFF, H. I.. Conceptual underpinnings of systematic strategic management. European Journal of Operational Research, v.19, n.1, p.2-19, 1985.

AZEVEDO, C. S.. Gerência hospitalar: a visão dos diretores de hospitais públicos do município do Rio de Janeiro. Rio de Janeiro, 1993.

BACHIR, P. M.; TRIKI, Y. R. R.. The Main Skin Diseases Encountered In Practice Canine In The Central Department Of Algeria. Agricultural Practice and Science Journal, v.77, n.1-2, 2011.

CARDOSO, M. J. L.; MACHADO, L. H. A.; MELUSSI, M.; ZAMARIAN, T. P.; CARNIELLI, C. M.; FERREIRA JÚNIOR, J. C. M.. Dermatopatias em cães: revisão de 257 casos. Archives of Veterinary Science, v.16, n.2, p.66-74, 2011.

D'INNOCENZO, M.; ADAMI, N. P.; CUNHA, I. C. K. O.. O movimento pela qualidade nos serviços de saúde e enfermagem. Revista Brasileira de Enfermagem, v.59, n.1, p.84-88, 2006. DOI: http://dx.doi.org/10.1590/S0034$\underline{71672006000100016}$

GIL, A. C.. Como elaborar projetos de pesquisa. São Paulo: Atlas, 2002.
HAMEL, G.; PRAHALAD, C. K.. The core competence of the corporation. In: Strategische Unternehmungsplanung: Strategische Unternehmungsführung: Stand und Entwicklungstendenzen. 1997. p.235-256.

LIN, B.; BRIAN, D. R.. Quality management in veterinary medical health care. Total Quality Management, v.7, n.5, p.451-458, 1996

MINTZBERG, H.. The rise and fall of strategic planning Londres: Pearson Education, 1995.

NEVES, J. L.. Pesquisa qualitativa: características, usos e possibilidades. Caderno de pesquisas em administração, São Paulo, v.1, n.3, p.1-5, 1996.

RICHARDSON, M.. Fundamentos da metodologia cientifica. São Paulo, 1999.

RUTHES, R. M.; CUNHA, I. C. K. O.. Os desafios da administração hospitalar na atualidade. Revista de Administração em Saúde, v.9, n.35, p.93-102, 2007.

VERGARA, S. C.; PECI, A.. Escolhas metodológicas em estudos organizacionais. Organizações \& Sociedade, v.10, n.27, p.13$26,2003$.

YIN, R.. Estudo de caso: planejamento e métodos. Porto Alegre: Bookman, 2001.

A CBPC - Companhia Brasileira de Produção Científica (CNPJ: 11.221.422/0001-03) detém os direitos materiais desta publicação. Os direitos referem-se à publicação do trabalho em qualquer parte do mundo, incluindo os direitos às renovações, expansões e disseminações da contribuição, bem como outros direitos subsidiários. Todos os trabalhos publicados eletronicamente poderão posteriormente ser publicados em coletâneas impressas sob coordenação da Sustenere Publishing, da Companhia Brasileira de Produção Científica e seus parceiros autorizados. Os (as) autores (as) preservam os direitos autorais, mas não têm permissão para a publicação da contribuição em outro meio, impresso ou digital, em português ou em tradução. 